\title{
La lettre et les lettres, entre-deux. Textes réunis par Claude Lachet et Laurence Richer
}

\section{Maria Colombo Timelli}

\section{(2) OpenEdition}

12 Journals

\section{Édition électronique}

URL : http://journals.openedition.org/studifrancesi/9415

DOI : 10.4000/studifrancesi.9415

ISSN : 2427-5856

Éditeur

Rosenberg \& Sellier

\section{Édition imprimée}

Date de publication : 1 décembre 2007

Pagination : 622-623

ISSN : 0039-2944

\section{Référence électronique}

Maria Colombo Timelli, « La lettre et les lettres, entre-deux. Textes réunis par Claude Lachet et Laurence Richer », Studi Francesi [En ligne], 153 (LI | III) | 2007, mis en ligne le 30 novembre 2015, consulté le 13 janvier 2021. URL : http://journals.openedition.org/studifrancesi/9415; DOI : https://doi.org/10.4000/ studifrancesi.9415

Ce document a été généré automatiquement le 13 janvier 2021.

\section{(c)}

Studi Francesi è distribuita con Licenza Creative Commons Attribuzione - Non commerciale - Non opere derivate 4.0 Internazionale. 


\title{
La lettre et les lettres, entre-deux. Textes réunis par Claude Lachet et Laurence Richer
}

\author{
Maria Colombo Timelli
}

\section{RÉFÉRENCE}

La lettre et les lettres, entre-deux. Textes réunis par Claude LACHET et Laurence RICHER, Lyon, CEDIC, 2006.

1 Quelques articles de ce recueil, qui réunit des séminaires de formation doctorale organisés au sein du CEDIC pendant les années 2003-2006, concernent la littérature médiévale.

2 Jean-Claude VALLECALLE, La lettre implicite: remarques sur les messages écrits dans l'épopée médiévale, pp. 9-23. Dans les chansons de geste des xiie-xiiie siècles, les lettres ne sont évoquées que de manière rapide et indirecte: comme le prouvent les exemples que J.C.V. tire d'Anseïs de Carthage, Aspremont, Chanson des Saisnes, Jehan de Lanson, le message oral prévaut nettement sur l'écrit. Au xive siècle seulement (par exemple dans la Belle Hélène de Constantinople ou Lion de Bourges), on relève un renouveau d'intérêt pour la lettre écrite, reproduite notamment lorsque le contenu en est mensonger et reflète un complot. Les épopées franco-italiennes (Entrée d'Espagne, Prise de Pampelune) constituent un cas particulier, dans la mesure où les lettres y sont inscrites dans un mètre différent (l'octosyllabe) qui les isole du contexte narratif et en souligne la spécificité; on peut expliquer cette évolution par la distanciation progressive entre l'écrivain et son œuvre, la lettre constituant en effet une interruption brusque de la parole du narrateur.

3 Danielle QUÉRUEL, Le roman de 'Tristan en prose': le premier roman épistolaire de la littérature française?, pp. 25-36. Consacrée spécialement aux échanges épistolaires dans les tomes I, IV, VII de l'édition dirigée par Philippe Ménard (Textes Littéraires Français), cette étude se propose de montrer comment les lettres, quels que soient leur forme (message en 
vers ou en prose, lai lyrique) et le messager chargé de les porter (demoiselle ou harpeur), jouent un rôle fondamental dans ce roman fondé sur l'entrelacement des aventures et par conséquent sur la distance physique des personnages.

4 Corinne PIERREVILLE, De la lettre au roman. Lecture, écriture et réécriture dans "Claris et Laris", pp. 37-63. Les missives étant très rares dans Claris et Laris, C.P. s'attache aux inscriptions tracées sur des supports très divers: lettres gravées à l'entrée de la forêt de Brocéliande, message inscrit sur une tour, inscription ornant une nef magique, lettres incrustées sur les murs d'une cité dévastée; par ailleurs, le mot 'lettre' désigne aussi (v. 9920) le roman lui-même. De plus, selon C.P., la large palette de motifs que l'auteur tire de la matière arthurienne, mais aussi des romans antiques, fait de ce roman une somme de la littérature médiévale, et de l'écriture une manière privilégiée de la préserver de l'oubli.

5 Claude LACHET, Les lettres dans "Le livre du Voir Dit" de Guillaume de Machaut: une recherche esthétique, pp. 65-81. Le Livre contient quarante-six lettres en prose, également réparties entre l'amant et Toute Belle, dont C.L. analyse le contenu et la structure, le lien avec le lyrisme et les jeux qu'elles cachent sur le nom de la dame, Peronne. Cette correspondance intime, imposée d'abord par l'éloignement des amants, s'avère être en même temps une réflexion sur l'amour pour la poésie.

6 Anne MARTINEAU, Les lettres dans "Ysaÿe le Triste", pp. 83-104. La quantité et la variété des messages écrits dans ce roman (rédigé entre la fin du xiv et le début $d u \mathrm{xv}^{\mathrm{e}}$ siècle) permet à A.M. de les examiner de plusieurs points de vue, de la fabrication à la transmission et à la réception sur le plan concret, puis, sur le plan culturel, comme témoignage d'un monde en évolution (généralisation des pratiques de lecture/ écriture), et encore sur le pian littéraire (intérêt esthétique, dramatique, psychologique et symbolique des messages). Conscient des possibilités offertes par les lettres, l'auteur leur confie la tâche de marquer la structure de son roman et d'en indiquer la signification profonde. 